\title{
All India Leprosy Workers' Silver Jubilee Conference
}

\author{
T. F. DAVEY
}

In October 1973, 500 leprosy workers from all parts of India met at Sevagram to pay tribute to the memories of Armauer Hansen and Father Damien, and also celebrate 25 years of association and cooperation in their specialized profession. It was entirely fitting that the Jubilee Conference should be held at Sevagram, near Wardha, a place of hallowed memory for all Indian patriots, for it was Gandhiji who called together here the first national gathering of leprosy workers in India, and it was in his own compassionate approach to leprosy patients that they found the inspiration for concerted action.

The Jubilee Leprosy Conference was the largest ever held in India, and from beginning to end the spirit and example of Gandhiji seemed to pervade it; in its simplicity, some might even say austerity, in its excellent fellowship and goodwill, and not least in the vegetarian catering, served with astonishing efficiency and expedition by a crowd of students rendering voluntary service.

The Conference was inaugurated by the Honourable Shri R. K. Khadilkar, Union Health Minister. While covering all the main aspects of leprology, and devoting special sessions to commemorating the centenary of Dr Hansen's discovery of Myco. leprae and Father Damien's arrival in Molokai, the Conference had its own Indian flavour in the emphasis given to problems surrounding epidemiology, control, and rehabilitation. At each session a high quality of contribution was assured by a rigorous curtailment of individual papers, most of the time available being filled by original papers from selected main speakers and shorter invited papers, with ample time for discussion. The following is an outline of material presented.

\section{Epidemiology}

Dr Dharmendra saw dangers in the assumption that a patient with zero M.I. is in a state of non-infectivity to others. Even if all non-solidly staining leprosy bacilli are non-viable, a zero M.I. means no more than that the number of non-viable bacilli in the body has fallen below the level at which they can be identified by standard techniques. Their numbers may however still be enormous. While the same limitation applies to a zero reading of the B.I., the criterion is much stricter, viz. no bacilli at all, solidly or non-solidly stained, being found in multiple skin smears in repeated examinations. Existing criteria of non-infectivity should not be abandoned. S. K. Noordeen, describing a longitudinal study over six 
years in a geographically limited rural community highly endemic for leprosy, reported a very high incidence of minimal lesions of tuberculoid type, with spontaneous regression a common feature, not only among children, but among adults. In a small proportion of patients showing regression, subsequent relapse occured. B. R. Chatterii, Jacob Thomas, C. E. Taylor and G. N. Naidu reported a study of a population of 7500 in a highly endemic area of West Bengal, kept under intensive epidemiological surveillance for six years. Standard routines included the examination of the ear lobes of asymptomatic individuals, contacts and others, for AFB, with the careful follow-up of all persons giving positive findings. The incidence rate of clinical leprosy was six times higher among such persons than in the general population. Incidence rates among nuclear family contacts of lepromatous/borderline leprosy were not significantly higher than in those of tuberculoid/indeterminate leprosy. Economic and crowding indices had no correlation with leprosy prevalence, but incidence rates were higher in the low income groups. The findings indicate that frequent examination with high population coverage is essential to define the basic epidemiology of leprosy. $R$. $J$. $W \cdot$ Rees and T. F. Davey presented recent clinical and bacteriological studies which emphasized the high prevalence and very high content of viable Myco. leprae in nasal discharges in early cases of lepromatous leprosy, and also indicated the capacity of Myco. leprae discharged from the nose to survive in a dried condition, $100 \%$ for $24 \mathrm{~h}$, significant numbers for 1.75 days, and a few for up to 7 days.

\section{Leprosy Control}

M. S. Nilakanta Rao presented data extending over 17 years of intensive leprosy control work organized by the Gandhi Memorial Leprosy Relief Foundation in selected areas. He concluded that after a few years of work by S.E.T. methodology the decline in incidence comes to a halt, suggesting a new ecological balance between the host and the infecting agent. Even though the quantum of infection in the community is reduced, new cases go on appearing in - almost equal numbers every year. This static position may give way if more potent drugs and modified methods of work are discovered. P. Vijay Shanker described a three-tier programme for attacking the formidable problem of urban leprosy control in Madras city, namely, full survey in slum areas covering approximately $33 \%$ of the city population, school surveys covering another $25 \%$, and health education covering the remaining $42 \%$. Health education methods suitable to various categories of people are an essential ingredient everywhere, aiming to prepare the community to accept leprosy on the same terms as other public health problems. Demonstration centres where leprosy is treated in integration with other health problems are being established. A paper on organization by $D$. D. Banerjee, Gangadhar Sharma and N. V. Nagabhusanam stressed the importance of health education and greater effort in the discovery of open cases.

\section{Experimental Medicine}

W. F. Kircheimer, guest of the Conference, described at first hand the work which has established the nine banded armadillo as a valuable animal model for the study of human leprosy. K. V. Desikan reported findings in mouse footpads harvested at varying intervals from 1-90 days after inoculation. A steep fall was 
found in the number of bacilli within the first week of inoculation, the yield falling to $20 \%$ of the original number.

\section{Immunology}

Tore Godal, guest of the Conference, described the detection of sub-clinical infection in leprosy by means of the lymphocyte transformation test (LTT) and the leucocyte migration inhibition test, and concluded that leprosy is more highly infectious than indicated by the prevalence of leprosy, and that sub-clinical infection commonly follows exposure to Myco. leprae. The relatively low response among contacts of active lepromatous patients was a surprising observation, which suggests that in such contacts "super exposure" to Myco. leprae can bring about a decrease in host resistance. N. H. Antia considered that the transfer of immunity by sensitized lymphocytes opens up new possibilities in the treatment of lepromatous leprosy resistant to the drugs available. Kunal Saha, M. M. Mittal, H. B. Maheswari and Col. R. N. Dutta reported some encouraging results in this direction in patients who received viable lymphocytes, but not in patients who received transfer factor only. I. Nath, J. Curtis, L. K. Bhutani, V. Mehra and G. P. Talwar found an increase in B-lymphocytes in most patients with lepromatous leprosy studied, but that a sub-population of T-lymphocytes was diminished.

\section{Impact of Leprosy Control on the Trend of Leprosy}

Summarizing the achievements of the past 25 years, $\operatorname{Dr} K$. C. Das, Assistant Director General of Medical Services (Leprosy), emphasized six aspects.

(1) The national leprosy control programme has now covered a population of 99 millions. 1.2 million cases of leprosy have been detected out of an estimated total of 3.2 millions for India as a whole.

(2) Through early diagnosis and treatment, large numbers of patients have been prevented from becoming infectious, and much deformity has been prevented.

(3) Reduction in incidence can only be expected after 15-20 years, but the quantum of infection is reducing at many centres and new cases are mostly of non-infective type.

(4) Leprosy is not dislocating the lives of patients on the same scale as formerly. Health education has led to less deformity and less social stigma.

(5) Research and training services have developed enormously and are of international importance.

(6) The ground work has been laid for a decisive nationwide attack, with the hope of controlling leprosy within 15 years.

C. Vellut stressed early and regular domiciliary treatment of all cases as the condition for success. Health education is of great importance in encouraging this. $V$. Ekambaram emphasized the greater interest being shown in the rehabilitation of patients, eye care, and the social aspects of the disease.

\section{Rehabilitation}

In an extremely valuable session, Anthony Swamy and Mrs Doraiappan both emphasized that rehabilitation must always be in the forefront of our thinking in 
every approach to patients from the very beginning, its primary object being to minimize disturbance to family and community life. Capt. Scott described much useful experience at an industrial rehabilitation centre, with his approach, "Judge by the abilities of a patient rather than by his disabilities". $R$. S. Sharma described an interesting experiment in agricultural rehabilitation at Dattapur. Occupational therapy was discussed by Monica Hopkins and Mrs Doraiappan.

\section{Health Education}

M. S. Mehendale pointed out the urgent need for proper orientation and training in health education relating to leprosy for health workers at all levels. Only through systematic training will vagueness, imbalance and inconsistency be eliminated and essential objectives be pinpointed. S.W. Ghokale saw health education as a self-help process, instilling a sense of responsibility for one's health and betterment, and so for that of the community as a whole.

\section{Social Welfare}

Papers by S. D. Ghokale, Paul Karipurath and Jagdish Deen all stressed the need for greater and united effort in promoting the social welfare of patients.

Full sessions of the Conference were devoted to medical and surgical management, and covered recent developments in both fields. In addition moving tributes to Armauer Hansen and Father Damien were paid by Prof. Johs Boe and T. N. Jagadisan.

This Conference amply demonstrated the wealth of experience, talent, and dedication found among the great body of leprosy workers in India, and which offer some hope that the formidable problems of leprosy control in India can be solved. The profound thanks of all concerned are due to the Organizing Committee of the Conference, and especially to Mrs Susheela Naya, Dr Nilakanta Rao and his staff. Their kindness, thoughtfulness and imperturbability made the occasion most memorable. 